\title{
Femininity and Job Satisfaction Among Male Library Students at One Midwestern University
}

\begin{abstract}
Male library science students at one midwestern university were found to have mean scores on the femininity scale of the California Psychological Inventory that were significantly greater than norms established by unselected samples of American men. Analysis of data also indicated that approximately one-third of the men participating in this investigation had been dissatisfied with a full-time job, or occupation, prior to entering library school. A statistically significant inverse correlation was found to exist between the amount of satisfaction these men experienced in such work and their score on the C.P.I. femininity scale.
\end{abstract}

$\mathbf{P}$

\section{INTRODUCTION}

generally agree that various occupations attract certain personalities to their ranks. Indeed this circumstance is so common that even the most untrained observer comes to associate given characteristics with such groups as car salesmen, research scientists, airline hostesses, and female bookkeepers. This being the case, should not librarians as an occupational class also manifest recognizable characteristics?

Various studies have shown that the mean age of library science students ranges from the late twenties to the early thirties. ${ }^{1}$ This would indicate that these people are older than the average age of students who have not yet gained experience in their first choice of occupation, a circumstance that probably occurs because most people who enter librarianship do so only after they have

Dr. Clayton is Professor, School of Library Science, University of Oklahoma. worked in some other field, usually teaching. Bryan, for example, found that two out of every five library students in her study had worked for at least one year in another area, and of this number, more than half had experience in teaching, with business, writing, and various intellectually related fields some distance behind. ${ }^{2}$

A persistent question among investigators is why these people abandon their first choice of occupation and, at a fairly advanced age, move to an entirely new field where they will have to make a substantial outlay in time and money just to acquire the necessary preparation. The importance of this question is heightened by the fact that librarianship typically offers neither greater remuneration nor higher status than the original occupation of these people. In such a context, this investigation attempted to determine whether distinctive personality characteristics-identifiable through statistical measurementcould be found among students of library science who were enrolled at a ma- 
jor midwestern university during the summer session of 1967.

\section{METHOD}

Data for this study were gathered by means of the California Psychological Inventory and a specially designed questionnaire. The participants were all 150 full-time library students enrolled at the University of Oklahoma during the 1967 summer session. Because the entire library school faculty made class time available for administering the C.P.I., each student was able to complete both the Inventory and the questionnaire with a minimum of personal inconvenience. While a procedure of this kind may suggest a captive audience, any such counteraction was hopefully mitigated by specifically asking the respondents not to identify their answer sheets in any way. Upon completing both instruments, each student merely placed all materials in a sealed, unmarked envelope and anonymously handed in the packet.

The C.P.I. is a standardized paperand-pencil test that concentrates on constructive achievement and positive aspects of interpersonal behavior. Because this investigation did not concern itself with weaknesses or defects in personalities, and because the C.P.I. attempts to provide insight into the growth and spontaneity of the subjects examined, it was felt that this particular inventory would be especially appropriate for a survey of this kind. Obviously, a number of limitations are inescapable when using standardized tests and statistical measuring tools; moreover, it is recognized that these data are indicative of only one group of students in one summer session, and for this reason there is no intention to project these findings to a larger area or to claim that the results are valid for all students in all library schools.

While eighteen personality variables are measured by the C.P.I., scores for men and women are always computed separately and discussed as unrelated groups. Regrettably, space limitations preclude a consideration of both sexes here, and as a result this article must concern itself only with the 35 males who participated in the investigation. Because this may at first seem like quite a small sample, it should be pointed out that (1) the 115 women subjects generated data that was quite similar to that of the men, and (2) persons who wish to examine the complete study can obtain a copy of the original report by writing to ERIC Document Reproduction Service, N.C.R. Company, 4936 Fairmont Avenue, Bethesda, Maryland 20014.

\section{Analysis of Data}

In general, biographical data concerning these 35 male library students paralleled that of previous investigations. Information from the questionnaire, for example, revealed an average age of approximately thirty-two years, with 25 men already past the age of twenty-six. In addition, at least two-thirds of these students had been employed on a fulltime basis before entering library school, none had worked in a library, and eleven of the 35 had teaching experience prior to this study.

Against this background, Figure 1, presents a profile depicting mean scores generated by the 35 male students on each of the C.P.I.'s eighteen personality scales. These mean scores are connected by dotted lines in such a way that by following the contour of the profile one can easily see how the overall elevation is below that of a composite profile which was derived by computing the means of fourteen adult occupational groups listed in the C.P.I. manual. ${ }^{3}$ The asterisks accompanying the actual scores (beneath the figure) indicate that thirteen of the librarians' eighteen means are so far below those of the 
Figure 1. Composite Profiles Generated from Mean Scores of 35 Male Library Students and 14 Occupational Groups

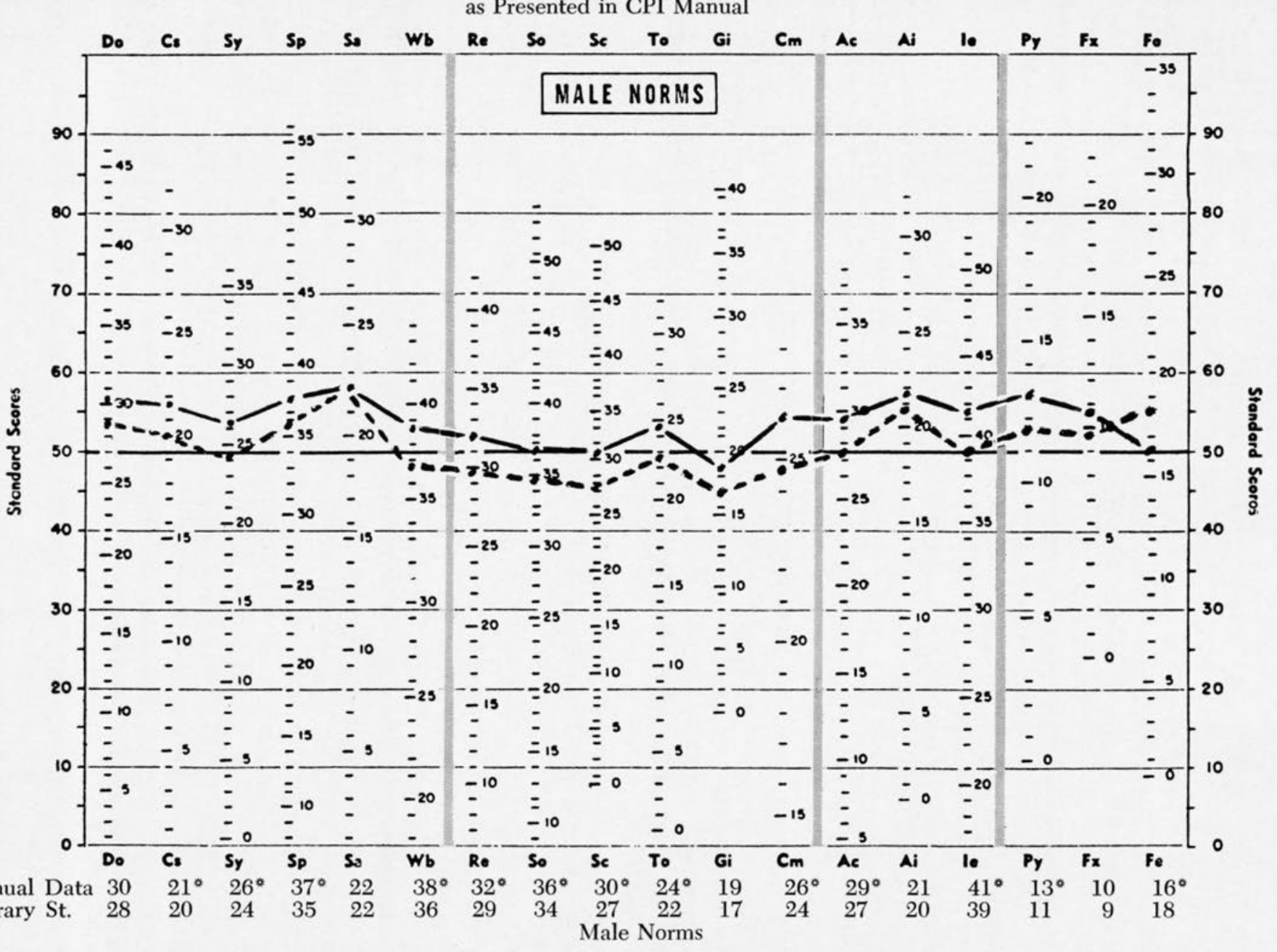


composite that such differences probably did not happen by chance. On the basis of this information, therefore, it would appear that these 35 male library students are not only lower than the composite on the first six scales (poise, ascendancy, and self-assurance), but also on the second set (socialization, maturity, and responsibility), and on the third set of scales as well (general orientation toward achievement and intellectual efficiency). Accordingly, it is only on the final scale (femininity) of the last set (interest modes) that these 35 library students score above the composite.

While such comparisons always make for lively conversation, one must be careful about reading too much into findings of this nature. In the first place, the author of the C.P.I., Dr. Harrison Gough, University of California, advises that composites which are generated from scores in the Inventory's manual can not be considered a national sample and should therefore not be regarded as norms. In addition, the means for these 35 library students, while consistently below the composite, still may not indicate serious deficiencies in any of the variables measured, for in no case do these group scores go as low as the first standard deviation below the mean-a point indicated on the profile sheet by a standard score of 40 and by the first horizontal line below the midpoint of 50. Yet despite such precautions in interpretation, a number of statisticians would contend it is significant that these library students did score below the composite on seventeen out of eighteen scales, for such an event could rarely happen by chance. Thus it would appear that as a group these library students are somewhat deficient, but not abnormally so, on seventeen of the eighteen characteristics which the C.P.I. is able to measure.

Another way of studying the personality structure of these 35 students is to determine how they differ from the way most persons answer each question in the Inventory. This can be done through an item analysis of all 480 questions in the C.P.I., a technique that will tell which items were answered true by library students more often than is normally expected, and which points were answered false more often than usual. In analyzing test questions in such a manner, one must first know the percentage of "true" responses which can be expected on each item from unselected samples. After this, it is necessary to select a cutoff point so that all items which exceed this point can then be separated for study. The author of the Inventory has established such percentages, and for this investigation a cutoff point of 25 percent above these norms was arbitrarily established. Therefore, if established norms indicated that 40 percent of all unselected samples answered a given question true, that Inventory item had to be answered by at least 65 percent of the library students before it could be used in this investigation. On the basis of such a determination, the points listed in Table 1 were identified. For clarity, the actual percentage of librarians answering true, plus the percentage of expected affirmative answers, are included in the brackets.

Equally pertinent are those questions that 25 percent fewer library students answered true. In the same manner as before, Table 2 shows the question number as it appeared in the Inventory, the percentage of male students who marked it true, and the percentage of true answers that should be expected on the basis of established norms.

\section{Femininity Among Male Librarians}

Using such information as background for understanding the entire sample, attention should now be directed to those data which resulted in the 
TABLE 1

CPI Questions that Were Answered AfFirmatively by Male Library Students More Frequently THAN BY UNSELECTED SAMPLES

\begin{tabular}{clcc}
\hline \hline $\begin{array}{c}\text { Question } \\
\text { Number }\end{array}$ & \multicolumn{1}{c}{ Text of the Question } & $\begin{array}{c}\text { Librarian } \\
\text { Percent }\end{array}$ & $\begin{array}{c}\text { Norm } \\
\text { Percent }\end{array}$ \\
\hline 122 & I like poetry. & 80 & 41 \\
124 & I am likely not to speak to people until they speak to me. & 34 & 6 \\
140 & I enjoy hearing lectures on world affairs. & 91 & 60 \\
204 & I like to plan a home study schedule and then follow it. & 68 & 34 \\
207 & Sometimes at elections I vote for men about whom I know very little. & 80 & 52 \\
217 & I think I would like the work of a librarian. & 97 & 13 \\
222 & I would like to belong to a discussion and study club. & 77 & 42 \\
246 & I like to plan out my activities in advance. & 88 & 22 \\
268 & At times I have been very anxious to get away from my family. & 80 & 55 \\
285 & I refuse to play some games because I am not good at them. & 68 & 33 \\
396 & I sometimes wanted to run away from home. & 68 & 44 \\
\hline
\end{tabular}

TABLE 2

CPI Questions that Were Answered Affirmatively by Male Library Students Less Frequently THAN BY UNSELECTED SAMPLES

\begin{tabular}{|c|c|c|c|}
\hline $\begin{array}{l}\text { Question } \\
\text { Number }\end{array}$ & Text of the Question & $\begin{array}{c}\text { Librarian } \\
\text { Percent }\end{array}$ & $\begin{array}{l}\text { Norm } \\
\text { Percent }\end{array}$ \\
\hline 18 & A person who doesn't vote is not a good citizen. & 37 & 66 \\
\hline 19 & I think I would like the work of a building contractor. & 14 & 44 \\
\hline 41 & For most questions there is just one right answer, once a person is & & \\
\hline 82 & $\begin{array}{l}\text { able to get all the facts. } \\
\text { think I would like the work }\end{array}$ & 26 & 56 \\
\hline 155 & $\begin{array}{l}\text { I think I would like the work of a garage mechanic. } \\
\text { A person should adapt his ideas and his behavior to the group that }\end{array}$ & 11 & 37 \\
\hline 100 & happens to be with him at the time. & 37 & 62 \\
\hline $\begin{array}{l}189 \\
241\end{array}$ & $\begin{array}{l}\text { In school my marks in deportment were quite regularly bad. } \\
\text { The man who provides temptation by leaving valuable property un- } \\
\text { protected is about as much to blame for its theft as the one who }\end{array}$ & 6 & 34 \\
\hline & & 34 & 59 \\
\hline 249 & I like mechanics magazines. & 34 & 72 \\
\hline 255 & Only a fool would try to change our American way of lif & 28 & 64 \\
\hline 263 & Lawbreakers are almost always caught and punished. & 37 & 63 \\
\hline 367 & My home life was always very pleasant. & 37 & 62 \\
\hline 382 & Success is a matter of will power. & 40 & 66 \\
\hline 416 & I don't think I'm quite as happy as others seem to be. & 17 & 42 \\
\hline
\end{tabular}

femininity score shown above in Figure 1. In discussing this scale, one must be careful to differentiate between the popular connotation of the word "femininity" and its meaning in the C.P.I. The underlying purpose of the entire scale is to act as a continuum which runs from low scores that signify such traits as initiative, capacity for making decisions, and assertiveness, to high scores which characterize persons of a conserving, maintaining, and restoring nature. In other words, one end of the femininity continuum is indicative of action and change while the opposite end symbolizes stability and nurturance. Perhaps the most important point insofar as the layman is concerned is that sexual normality is ordinarily expected of the subject under study, regardless of his score on this particular scale.

With this introduction, attention should be directed to Table 3 . In this tabulation, data from 6,419 American 
males is presented which, in showing norms for the femininity scale, indicates the mean is approximately 16.26 , with a standard deviation of 3.63. In contrast to these data is the fact that library students have a mean of 18.17, and a standard deviation of 2.95 . When put to a " $\mathrm{t}$ " test, such a difference proves to be statistically significant at the .01 level of probability, all of which indicates that in comparison to the norm, this group of library students tends toward that end of the scale which is known for gentleness and appreciativeness, rather than ambition, activity, and innovation.

Such tendencies become even more pronounced when one observes that in Table 3 only two library students have raw scores (viz., 12 and 13) that would be plotted near the first negative standard deviation in Figure 1. As pointed out earlier, standard deviations are breaking points where fairly clear indications of a characteristic become apparent. Therefore, of the 35 library students in this study, only one would seem to be a candidate for such adjectives as manipulative, opportunistic, hardheaded, impatient, and oriented toward action and change; only one other student is even close to the point where he could be described in similar terms.

On the other hand, there are at least twelve male library students in Table 3 who are one standard deviation or more above the mean of the profile chart in Figure 1. Such a circumstance is of utmost importance for it means that these scores would form a rather elevated distribution if plotted on a profile sheet similar to that found in Figure 1. If this distribution were normally scattered around a standard score of 50 , as are the American male norms, there would be 23.8 scores within the first standard deviation, and 5.6 scores both above and below the first standard deviation. With $\mathrm{p}<01$, a goodness of fit test confirmed that there are indeed too many scores above the first standard deviation, or in that range where characteristics associated with high scores on femininity begin to be pronounced.

\section{Satisfaction Scale}

As noted earlier, the literature consistently shows that a high percentage of library students have typically worked at some other occupation before entering the field of librarianship. Because most people do not wait until they are well into their adult years before entering a profession which requires a

\section{TABLE 3}

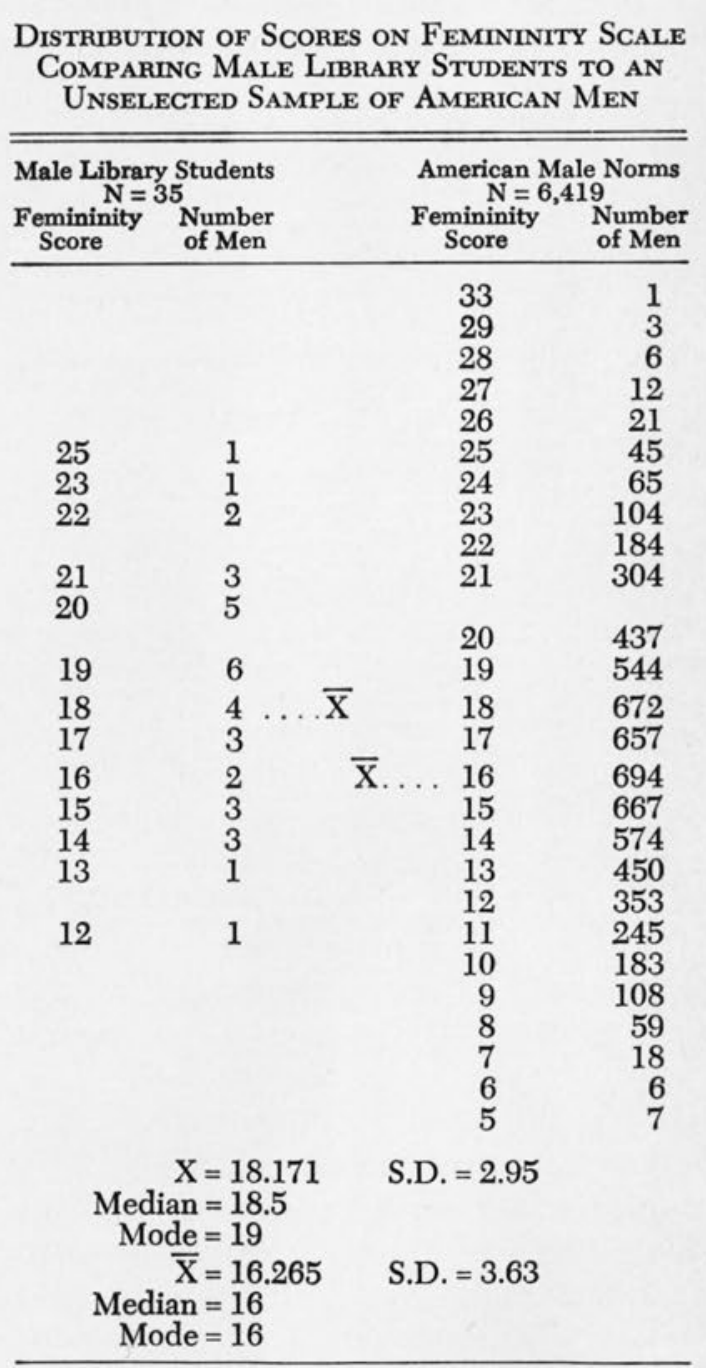


substantial outlay of time and money just to acquire minimum credentials, important factors must be at work which cause a person to desire training in library science. An interesting speculation might be made on the amount of satisfaction a person realized from his previous work, for surely most people stay with the same general kind of work if it is giving them substantial satisfaction. In an attempt to determine whether past job satisfaction is in any way associated with scores which these library students generated on various C.P.I. scales, each participant was asked to rate the amount of satisfaction he derived from whatever type of work he was doing before entering library school. In making these self-ratings, the student mining job satisfaction, for it is a matter of interpretation as to how much satisfaction and dissatisfaction an employee is reflecting when he rates himself at any given number.

But if it is assumed that such use of the standard deviation is a valid device for determining occupational satisfaction, some thought-provoking findings will quickly come to light. Figure 2, for example, presents mean profiles for the two groups of men who occupy these high and low satisfaction categories, and from this graph it is clear that dissatisfied students have lower elevations on all C.P.I. scales except femininity. By the use of " $t$ " tests, significant differences between these scores are apparent on at least seven of the Inventory's

TABLE 4

Distribution of Self-Rankings Indicative of Satisfaction Which 35 Male Students Realized from Full-Time Work Prior to Entering Library School

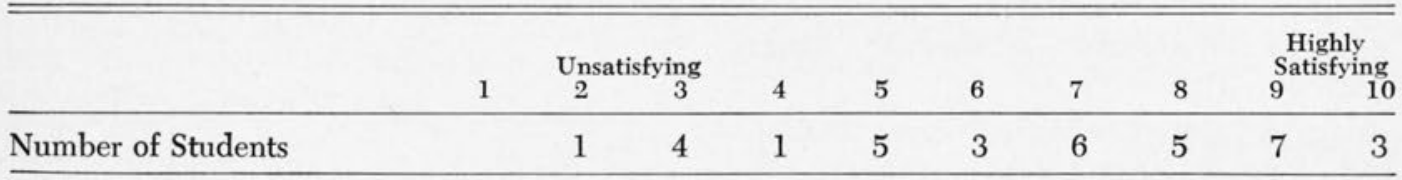

merely placed a check mark on a 10 point rating scale that represented a continuum running from unsatisfying to highly satisfying.

Table 4 shows how these 35 library students checked this Satisfaction rating scale. The mean score on these ratings was 6.74 , with a standard deviation of 2.29 ; accordingly, only "9" and " 10 " on the scale would mathematically show a high level of satisfaction, and ratings " 1 " through " 4 " would be considered unsatisfying. On this basis, Table 4 indicates that only ten of the 35 men could be considered as truly happy with their former work, while six students would have to be characterized as occupationally dissatisfied. Quite obviously this is a questionable method of deter- eighteen scales. Moreover, as was the case in Figure 1, the direction of these differences is also important, for in terms of statistical probability they could hardly have occurred on seventeen out of eighteen scales simply by chance. But perhaps the most important finding pertaining to these six men is that they accumulated a mean score of 20.3 on the femininity scale, a score that places the entire group slightly above the first standard deviation. In light of this circumstance, the five men who rated themselves at " 5 " on the Satisfaction scale were added to this subsample, and upon completing the necessary computations it was seen that this new group of eleven students generated a femininity score of 20.1, or still beyond the profile's first standard deviation. 
Figure 2. Composite Profiles Generated from Mean Scores of Male Library Students with High and Low Self-Ratings

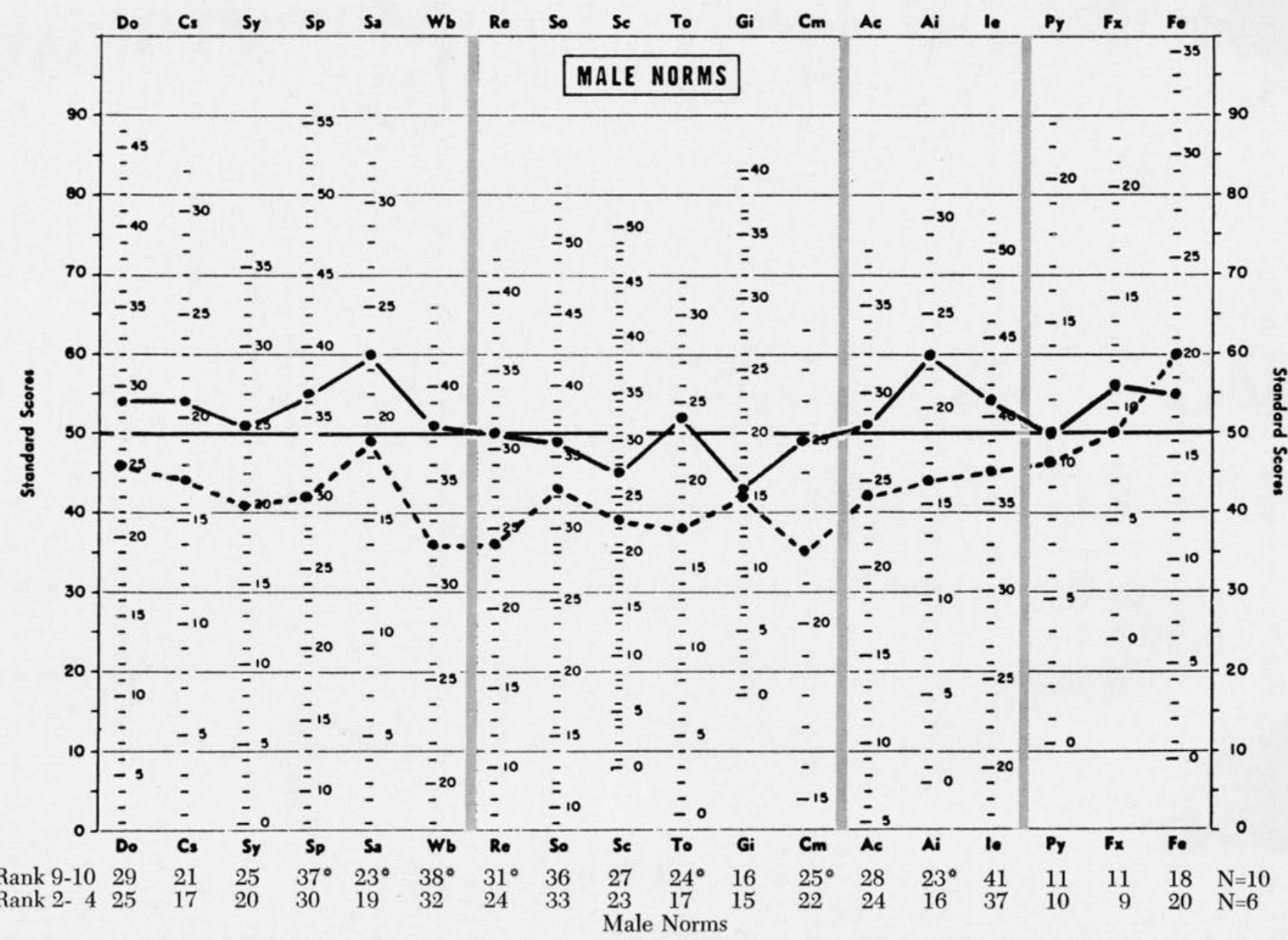


The satisfaction scale also proved useful when a correlation test was taken to discover if any association existed between the self-ratings of the entire sample and scores on the femininity scale. In this case, there was an inverse correlation, $\mathrm{r}=-.387, \mathrm{p}<.05$, between the ratings of all 35 students and their femininity scores; while correlation does not mean cause and effect, such a finding does indicate that low self-raters on this satisfaction scale were more likely to be high scorers on femininity.

At the same time femininity was found to be inversely associated with satisfaction, positive correlations were found between these self-ratings and the sociability, social presence, self-acceptance, and responsibility scales. The exact coefficients on each of these tests were as follows:

$\begin{array}{ll}\text { Sociability } & +.317 \\ \text { Social Presence } & +.287 \\ \text { Self-Acceptance } & +.316 \\ \text { Responsibility } & +.286 \\ \text { Femininity } & -.387\end{array}$

Although the entire contour of a profile must be analyzed if one is to appreciate the personality being studied, these five scales in combination do present a certain constellation of characteristics. In general, high scores on sociability, social presence, self-acceptance, and responsibility, when coupled to a low score on femininity, indicate a person who is enthusiastic, resourceful, outgoing in a self-confident yet dependable way, progressive in a planned manner, but impatient with those who are too reflective. Conversely, low scores on the first four of these scales, together with a high score on femininity, indicate a person who is moderate, respectful, conservative, who behaves in a conscientious way, but who is somewhat awkward and narrow in his interests.

At this point it is well to remember from Table 3 that twelve of the 35 students, or virtually one in three, have femininity raw scores which-when plotted on a profile sheet-are above the first standard deviation. Interestingly enough, these twelve men have a mean self-rating on the satisfaction scale of 5.6 , with a standard deviation of 2.59 . In contrast, the twenty-two men of Table 3 who are inside the first standard deviation have a mean satisfaction rating of 7.3, with a standard deviation of 1.82. In a " $t$ " test for significance, this mean of 7.3 proved to be bigger than 5.6 with $\mathrm{p}<.025$. Such a finding suplies further evidence that it is from this disproportionately large number of high scores on femininity that one is most likely to locate those who were dissatisfied with what they were doing before entering library school.

\section{Summary and Conclusions}

In comparing a sample of 35 male library students to a composite profile generated from data in the C.P.I. manual, it was found that the students had lower mean scores on all of the Inventory's eighteen scales except femininity. Upon further investigation, it became clear that the students' higher score on femininity was also greater than the scale's established norm; moreover, additional inspection showed that only one library student was as much as a single standard deviation below this norm, while twelve students were at least one standard deviation above such a point.

Equally important were the data generated from a 10-point satisfaction scale. In this case, the entire sample of 35 male library students gave themselves a mean rating of 6.74 on a scale in which "1" was considered unsatisfying and " 10 " was denoted as highly satisfying. Testing revealed that the six most dissatisfied students not only had a lower group C.P.I. profile than the highly satisfied raters, but it also showed that on the femininity scale these six dissatisfied students had a mean score that was above the first standard deviation on the 
profile sheet. Then, as a matter of interest, those five students who rated themselves on the satisfaction scale at " 5 " were added to the six males who rated themselves no higher than " 4 ." When this was done, the new total of eleven students produced a mean femininity score of 20.1 , a score that was still above the first standard deviation on the profile sheet.

The twelve students who were above the profile's first standard deviation on femininity were found to have a mean satisfaction rating of 5.6. Conversely, those 22 students who were inside the first standard deviation had a mean selfrating of 7.3. By means of a " $t$ " test, this difference proved to be statistically significant with $\mathrm{p}<.025$. Finally, a statistically significant inverse correlation was found between all 35 satisfaction ratings and separate scores on the femininity scale, while a positive correlation was found between the satisfaction ratings and the sociability, social presence, self-acceptance, and responsibility scales.

Briefly stated, then, there were twelve students-or one out of every three in this investigation-who were above average on femininity and who together had a mean satisfaction rating of 5.6. By the same token, there were six students who were mathematically below average on satisfaction and five more students who, on a 10-point scale, rated themselves no higher than " 5 ." Together, these eleven men had a femininity score of 20.1, a score that placed them above the first standard deviation on the C.P.I. profile sheet. From this it seems clear that those highest on femininity were the ones who were most dissatisfied with former work. In conclusion, a correlation test indicated that an association did exist between high scores on femininity and low ratings on satisfaction.

As is the case with all statistical studies in the behavioral sciences, results such as those reported here often raise more questions than they answer. No one knows, for example, whether high scorers on the C.P.I.'s femininity scale make good, bad, or average librarians. Moreover, no one knows whether adult men who were dissatisfied with former work will be satisfied or more dissatisfied as librarians. Nor does anyone know whether the number of dissatisfied men found in this study is out of proportion to either the population as a whole or to what one would find in any investigation of various occupations. In fact, this entire field is such an unexplored area that no one even knows what type of personality makes the best librarian.

What these findings do indicate is that this sample of library students has a higher mean score on the C.P.I.'s femininity scale than American men as a whole. Related to such a finding is the fact that high scorers on the C.P.I.'s femininity scale typically manifest characteristics that can be described as patient, sympathetic, and appreciative. In the absence of evidence, of course, one might easily make a case that these are the very traits which people most want to find in library workers; certainly it is doubtful if many persons want to be greeted in a library by professional personnel who manifest the antitheses of such characteristics.

But even if this is granted, there is still room for concern about the number of low profiles that seems to be associated with lack of job satisfaction. Because these men as a group were similar in several respects to samples reported in earlier studies, the temptation is to generalize on the bases of these discrete pieces of information and say that available evidence indicates that librarians tend to be refugees from certain identifiable occupations, usually professions which are strongly competitive (e.g., music, literary, and artistic) or which are known to have considerable stress and tension (e.g., teaching). However, in searching for a new occupation, 
it seems that these people still want to be in a line of work that is basically intellectual and education-oriented.

The present study is intended only as a pilot project which needs to be replicated in many different settings. If this could be done, the results might provide background for a nationwide survey which could determine whether personality factors have anything to do with a person becoming dissatisfied in one line of work and subsequently turning to librarianship. In addition, separate studies could be undertaken to determine what type of person makes a successful librarian, what type is actually entering the ranks of librarianship, and what, if anything, is needed to entice certain personalities into librarianship. At this point, some find it difficult to see how librarianship can ever become a well-established profession if a substantial proportion of its members do enter the field only after they become dissatisfied with their first choice of occupation.
Many persons in higher education feel the academic library of today has a special need for imaginative people with innovative ideas. If there is any validity to the long-cherished sentiment that a library is central to education, then it seems self-evident that librarians must be as enterprising and ambitious as others who participate in the teaching-learning process. When considered in this context, the academic library of tomorrow will probably have to be staffed by personnel who manifest more aggressiveness and less nurturance than is exhibited by students in this investigation. A willingness to serve is important, and a kindly spirit is always appreciated, but conviction in what one is doing could be even more important; when matched to enthusiasm and resourcefulness, the result may be what academic librarianship is most in need of, namely, positive-minded persons who are goal-oriented and anxious for improvement.

\section{REFERENCES}

1. Anita R. Schiller, Characteristics of Professional Personnel in College and University Libraries, with the assistance of James W. Grimm and Margo C. Trumpeter, Research Series No. 16 (Washington, D.C.: Bureau of Research, U.S. Office of Education, 1969), p. 23. J. M. Whittock, "Study the Interests of the Female Students Enrolled in the School of Library Science, Drexel Institute of Technology, as Measured by the Strong Vocational Interest Blank and the Kuder Preference Record" (Unpublished M.L.S. thesis, Drexel Institute of Technology, 1952). R. R. Douglas, "Personality of the Librarian" (Unpublished
Ph.D. thesis, University of Chicago, 1957), p. 56 .

2. Alice Isabel Bryan, The Public Librarian; A Report of the Public Library Inquiry (New York: Columbia University Press, 1952).

3. Occupational groups included in the composite profile are: salesmen, bank managers, business executives, correctional officers, school superintendents, machine operators, psychiatric residents, practicing dentists, architects, research scientists, psychology graduate students, medical school applicants, social work graduate students, and military officers. 